\title{
Transition of new dental graduates into practice: a qualitative study
}

\author{
Urzinger, Sebastian
}

http://hdl.handle.net/10026.1/5160

10.1111/eje. 12143

European Journal of Dental Education

Wiley

All content in PEARL is protected by copyright law. Author manuscripts are made available in accordance with publisher policies. Please cite only the published version using the details provided on the item record or document. In the absence of an open licence (e.g. Creative Commons), permissions for further reuse of content should be sought from the publisher or author. 
"This is a final author's draft of the paper submitted for publication in European Journal of Dental Education 2016 DOI: http://dx.doi.org/10.1111/eje.12143".

Title

\section{Transition of New Dental Graduates into Practice: A Qualitative Study.}

K. Ali ${ }^{1}$, C. Tredwin ${ }^{2}$, E.J. Kay ${ }^{3}$, A. Slade ${ }^{4}$

${ }^{1}$ Associate Professor, Peninsula Dental School, ${ }^{2}$ Head of Peninsula Dental School, ${ }^{3}$ Foundation Dean,
Peninsula Dental School, ${ }^{4}$ Lecturer Occupational Health, Peninsula Allied Health Centre (PAHC),
Plymouth University, PL6 8BH

Correspondence Author: Kamran Ali

Peninsula Dental School

Portland Square

University of Plymouth

Drake Circus

Plymouth

PL4 8AA

E-mail: kamran.ali@plymouth.ac.uk 


\section{Abstract}

Aims: The aims of this study were to explore the transition of new dental graduates to gain a deeper understanding of the merits and challenges of a mentored year for new graduates in general dental practice settings.

Methods The study was conducted in the South West region of England. Qualitative methods were used to engage a range of stakeholders in dental education including dental students, academics, general dental practitioners, new graduates, specialists and representatives of the postgraduate dental deanery. Purposive sampling was employed and after ethical approval, participants were contacted through professional channels. All interview transcripts were transcribed verbatim. The data were imported into NVivo 10 (QSR International Pty Ltd) and analysed thematically.

Results Sixteen participants representing a variety of stakeholder groups were interviewed. The participants shared their perceptions and experiences regarding the transition new dental graduates into dental practice. The challenges and benefits are discussed along with strategies to facilitate a smooth transition.

Conclusions This study provides an insight into experience of a mentored year for new dental graduates in general practice settings. Foundation training provides a structured introduction into general practice and serves as a safety net before new graduates gain further independence in clinical practice. 


\section{Introduction}

Dental students are expected to acquire a high standard of cognitive, psychomotor and affective skills during the undergraduate programme. A unique aspect of undergraduate education in dentistry is that it involves performing irreversible operative procedures on patients for which the students are personally responsible. Clearly, due to the high levels of competence required in operative skills, dentistry can be a demanding and often stressful experience for the students $(1,2)$. Furthermore, transition into general practice following graduation poses additional challenges for new dental graduates.

The concept of competence is not new and can be traced back to several centuries amongst the Greeks, Romans and Persians. In more recent times, interest in competence-based education initially re-surfaced in the United States in the seventies of the last century (3) and was predominantly aimed at improving behaviour-oriented skills which subsequently shaped the design of vocational technical courses. Following the Bologna Declaration, the last 15 years have witnessed a strong trend towards Europeanization of higher education (4). However, instead of a behaviour-oriented skills approach the European initiatives have adopted a more integrated approach of developing unified clusters of knowledge, skills and attitudes that facilitate an introduction into a field of study and subsequent transition into work environments (5).

In parallel with other areas in higher education, the Association for Dental Education in Europe (ADEE) is working toward harmonization and convergence of dental curricula across Europe $(6,7)$. Dental educators in Europe have agreed on the profile of the graduating dentist. According to the profile and competences for a 
European dentist, as agreed by the general assembly of ADEE, "A dentist must have acquired this ability through the achievement of a set of generic and subject specific competences - abilities essential to begin independent, unsupervised dental practice. This should be achieved by the time he or she obtains the first professional degree". Professionalism, interpersonal, communication and social skills, knowledge base, clinical information gathering skills, diagnosis and treatment planning, therapy and prevention have been identified as the broad categories of professional activity and concerns that occur in the general practice of dentistry. In the United Kingdom (UK), the General Dental Council (GDC) has also prescribed learning outcomes for dentists (8) focusing on a competency-based framework in four key domains namely; clinical, communication, professionalism and management and leadership. The GDC learning outcomes are broadly similar to the ADEE profile.

The move of dental graduates from the University environment into the dental practice represents a critical transition in the continuum of dental education. However, there is a paucity of published literature regarding the dynamics and structure of transition of dental graduates across Europe. In UK, newly qualified dental graduates spend a mentored year in general dental practice settings under a scheme known as foundation training. Formerly known as Vocational training (VT), foundation training was initially started as a voluntary scheme for new dental graduates in UK as early as 1977. However, in 1993 a one-year period of training subsequently became a mandatory requirement for all newly qualified dental graduates in UK who intended to practice within the National Health Service (9). The GDC strongly endorsed this arrangement, which 'allows a gradual and controlled transition from the shelter of undergraduate education to unsupervised practice' (10). 
There is a general understanding that one year of foundation training is a protected period which is essential to allow the transition of a relatively inexperienced undergraduate to an independent dental practitioner. Although all dental schools strive to comply with the GDC learning outcomes for new graduates (8), there is evidence this may not always be achieved and the transition into general dental practice programme remains a demanding milestone $(11,12,13,14)$.

Historically, pedagogy in medical education has been influenced by a variety of theoretical perspectives including behaviourist, cognitivist, humanist, social and constructivist theories of learning (15). However, these theories largely view learning as an individual activity (16). Advances in medical education have influenced educators to view health-care education through the lens of sociology and anthropology to capture all the influences and interactions that transpire in the learning environments through active engagement of the learners (17). The conceptual framework of this research is based on the theory of Situated Learning (18). Situated learning asserts that learning is always intricately tied to its context and to the social relations and practices. It emphasizes the social nature of cognition, and the importance of authentic situations and activities to facilitate learning (16). In the context of dental education, the dental profession represents a fraternity who come together in pursuit of a shared enterprise. The role of a dental student may be viewed as one of legitimate peripheral participation (18). The newcomers begin learning at the periphery of the dental community, initially by observing and later by performing basic tasks. As they become more knowledgeable and skilled, they move centrally. Through participation, active engagement and assuming increasing 
responsibility, the newcomers acquire the roles, skills, and values of the culture and community.

Most studies on dental graduates primarily centre on strengths and weaknesses in the clinical skills of new graduates using pre-designed questionnaires. However, there are few studies exploring the experience of transition following graduation (19, 20). The aim of this study was to gain a deeper understanding of the concept of preparedness of dental graduates and how the transition is perceived by a range of stakeholders. The issues related to preparedness have been discussed in another paper (21) and this paper focuses on the challenges related to the transition of new graduates into foundation training. The findings of this study may be of interest to dental educators in Europe and beyond to as it highlights the merits and challenges of a mentored year in general dental practice following graduation. 


\section{Methods}

This study was undertaken in the South West region of England using qualitative methods i.e., semi structured interviews. Purposive sampling technique was done to recruit a range of stakeholders including dental students (DS), dental academics (DA), foundation dentists (DF), foundation trainers (FT), and general dental practitioners (GDP). Semi structured interviews were used to explore the perceptions of the participants with regard to transition of dental graduates into foundation training. Ethics approval was obtained from the Research Ethics committee of the institution. The participants were recruited through e-mail invitation using professional channels. Sixteen participants were recruited (three participants from each of the five stakeholder groups, along with a regional deanery representative).

Interviews were carried out in quiet rooms at a university in South West England. Some interviews were also conducted in a quiet room at local dental practices where some participants were based. The researcher obtained an informed consent from each participant prior to commencing the interview. The participants were also reminded that the interviews would be recorded and were provided an opportunity to express any concerns. The role of the principal researcher and their professional capacity was made clear to each participant i.e., the researcher is a full-time clinical academic based at a local dental school. A topic guide was developed to guide the course of the interviews. Initially each participant was asked to explain their professional role which helped to break the ice. This was followed by a few openended questions to explore the perceptions of the participants regarding transition of new graduates into general practice, essential attributes of preparedness, potential challenges and strategies to facilitate a smooth transition. Two pilot interviews were 
undertaken to determine the practicalities of interviewing process and ensuring the method is appropriate to address the research questions. Participants were given complete freedom to express their views by consciously avoiding any interruptions. A mirroring technique was used to explore the responses of the participants in further detail with a focus on meaning and experience of various groups of stakeholders rather than generalised patterns of behaviour. Prompts were used if the initial responses of the participants were brief. Some initial reflections were made on paper immediately after each of the interviews to record any observations about the interview. Following initial look at the data gathered during each interview, the topic guide was refined in successive interviews in order to gain an in-depth understanding of the emerging themes. The aim was to capture how the participants differ as much as what they have in common. The interviews were recorded using a digital audio device to allow the researcher to revisit the original data as often as necessary. All interviews were transcribed verbatim by the researcher within ten days of each interview. The transcripts were anonymised using pseudonyms to protect the identity of the participants. The accuracy of typed transcript was confirmed with each participant electronically.

The data were imported into NVivo 10 (QSR International Pty Ltd) and an initial coding of the data was carried out by systematic reading through the entire data set sentence by sentence. Initial coding as free nodes resulted in 114 nodes. Repetitive revisiting of the transcripts, audio recordings and the accompanying notes helped to collapse the nodes into broader codes. A thematic analysis of the data was carried out using an inductive approach i.e., the themes were data driven and were not categorised on the basis of questions asked in the interviews. An iterative process of 
categorising and re-categorising was involved in the thematic analysis. Further analysis and reflection helped to establish tree nodes from free nodes which finally crystallised into the themes. Data analyses were validated by comparison with analysis of transcripts by two independent researchers to verify the seeming accuracy of the category system. Following deliberations, minor modifications were made to the coding of the data and categorisation under various themes. The results were shared with four participants (a dental academic; a general dental practitioner, a foundation trainer and a foundation trainee) to ensure interpretation of the data were consistent with their views. 


\section{Results}

Sixteen participants (9 males and 7 females) were interviewed with equal representation of various stakeholder groups. These included 3 experienced dental academics, three final year undergraduate students from a local dental school, 3 foundation trainers, 3 foundation dentists (at various stages of training), and 3 general dental practitioners in the South West region of England. In addition, the regional postgraduate Dean also participated in the study.

The participants expressed their views on a range of issues related to the preparedness of new graduates, reasons for gaps in training, challenges of transition, and also suggested strategies to improve preparedness. The main themes related to transition are discussed in this paper along with excerpts from interview transcripts.

\section{Perceptions of Transition into Foundation Training}

Participants had mixed perceptions regarding the transition with some participants regarding it as a stressful experience with multiple challenges while others perceived it to be a generally smooth process. Time management in the face of increased workload, and expectations of patients and trainers were the key challenges perceived by the dental students and foundation dentists. While the dental academics and foundation trainers shared some of these concerns, they considered establishing professional relationships with the dental team was a key factor to facilitate a smooth transition. Nevertheless, representatives of all stakeholder groups affirmed the need for a mentored year in general dental practice setting for new graduates and regarded transition into foundation training as an exciting milestone for professional development. 
"I've been around the block enough to accept that and recognize the importance of a mentored year and in order for them to consolidate their learning and actually apply their knowledge and hopefully transfer that to becoming an expert. Probably it is the best thing for dentists who are graduating. I wish that every dental school in Europe had foundation training because it would save a lot of trouble”. (FT 2)

It appears that although the new graduates were concerned about working in a new environment, they looked forward to it and generally settled down well.

"My experience has been good. The practice is very well prepared for VT; they have been doing it for ten years. The nurse always works with the majority of the year, which is really good at the start and that was something I worried about".

Perhaps it is understandable for a new graduate to be apprehensive of working in a new settings coupled with uncertainties regarding the expectations of their future trainer. Like the foundation dentists, trainers also agreed that generally the new graduates settle down within the first couple of months.

Foundation training was seen as a sharp learning curve but one which provided an opportunity for rapid professional development. While the dental students realised prospects of future training, the foundation dentists shared their actual experiences and expressed how quickly training in practice improved their clinical confidence.

"I think, four years of dental school could fit into a week at practice. Yeah it's incredible to think how quickly you learn once you get into practice as opposed to the time spent in training". (DF 1) 
"My confidence in my dentistry sky-rocketed in the first few weeks of practice, much more than it did over the four years but I think that's just because you are seeing more patients, you are cracking on". (DF 3)

Given that new graduates have had teaching and training in basic clinical dentistry, it is understandable that experience in general practice allows rapid consolidation of clinical skills. Unlike the departmental organisation of most dental schools and hospitals, general practice settings provide exposure to a variety of patients requiring a range of treatments on a daily basis. The foundation dentists are responsible for patient assessment, treatment planning, treatment delivery and follow-up, allowing a more holistic experience. Moreover, training does not involve extensive daily teaching activities, routine examinations or academic assignments, which helps the trainees to focus on their clinical and team-working skills.

However, representatives of students, foundation dentists and dental academics regarded adequate support from the trainer and nursing staff crucial for a seamless transition. This is particularly important during the initial period when the work environment and colleagues seem unfamiliar to a newly qualified dentist.

"The way the practice is setup is important, whether you can ask for help, whether you feel safe enough to ask for help without being feeling to be criticised. My experience has been good. The practice is very well prepared for VT; they have been doing it for ten years. The nurse always works with the majority of the year, which is really good at the start and that was something I worried about". (DF2).

"This will vary from student to student as a graduate and from practice to practice. Where they have an experienced trainer and an experienced dental nurse with them, 
they'll find it easier. If they are put under pressure to become too fast too soon, that will be an issue". (DA 2)

A supportive practice environment may be achieved in a number of ways including allocation of a dedicated experienced nurse, regular briefing and debriefing sessions by the supervisor before and after each clinical session respectively. Although the trainers may spend part of their time treating patients themselves, they need to ensure their trainees are not hesitant to ask for help when in difficulty. As suggested by one foundation trainer (FT2), having their trainee's surgery in close proximity allowed them to keep a close eye and identify when they are in difficulty, may also be helpful.

\section{Challenges of Transition}

\section{a) Recruitment for Foundation Training}

Recruitment of dentists for foundation training in UK has been centralised recently and places are allocated based on a national ranking system. The process of recruitment is carried out during the final year of study and it was regarded as an initial challenge, primarily due to its competitive nature.

"The whole country-wide ranking system must be very stressful for the students. I have watched them being much stressed about it and I do feel sorry for them. I think it is very difficult for them". (FT2)

Centralised recruitment which was introduced in 2011, presents specific challenges to various stakeholders. The recruitment is no longer at the discretion of individual deaneries and the foundation trainers do not have a direct control over the trainee allocated to their practice. Applicants need to state a preference order for each of the 
74 training schemes and are offered a place on the basis of ranked scores achieved and stated preferences. The students appear for the selection process in their final year and often regard it as an additional hurdle prior to the finals examination. The dental academics are also under increasing pressure to provide structured training for the selection process which adds to their workload. Although various stakeholders have their concerns, the deanery representative felt that the national recruitment scheme is probably more fair and transparent and more amenable to quality assurance. Perhaps it may be premature to pass a judgement on the relative merits and demerits of national recruitment and further experience may better inform the stakeholders.

\section{b) Increased Patient Load}

Increased patient load with relatively limited time surfaced as a major concern for dental students and foundation dentists. The participants felt that unlike the dental school environment, they do not have freedom of long clinical appointments. Working under tight time schedules was regarded as a major challenge by prospective and recent graduates.

"There is a level of expectation about the number of patients you will see in a day and if you have to treat a certain number of patients, you may be quite restricted in terms of the time available for each appointment". (DF 1)

Effective time management to treat a larger number of patients was mentioned as a concern by all dental students and the new graduates. Although the concern was appreciated by foundation trainers, they felt new graduates tend to get better at time management after the initial few months in training. Simulated dental practice 
training during undergraduate years was suggested as an appropriate strategy to enhance clinical time management skills (see next section).

\section{c) Increased Responsibility}

The dental students were of the view that the dental schools provide a more sheltered environment with direct supervision while there is a greater responsibility with an added risk of litigation in the foundation year.

"I think it's a normal psychological aspect of thinking that we are protected here and if something happens there is always a supervisor to bail us out. That is not always going to be possible once you are finished and this scares a lot of people". (DS 1).

Like all clinicians, foundation dentists also require a professional indemnity cover to deal with potential litigation by patients. Although anecdotal evidence does not suggest that patients' complaints against foundation dentists are particularly high, foundation dentists also seemed to be concerned about the risk. The foundation trainers, dental academics and the deanery representative were of the view that the new graduates can significantly minimise the risks of litigation by acting within the limits of their professional competence, reflective practice, good communication skills and actively seeking help from their trainer when required.

\section{d) Increased Patient's Expectations}

New graduates felt they had limited clinical experience and this coupled with increased workload and responsibility mentioned before, poses a particular challenge when treating patients in general practice. Patients in practice pay for their treatment and may have higher expectations than those at the dental school. Patients may regard the foundation dentist as having limited clinical experience and 
may have less confidence in their skills compared to those of an experienced practitioner.

"I was inexperienced, didn't want really people to think I was inexperienced. So I was a bit scared of saying it won't work". (DF 2)

"If someone needs extensive treatment, where they may be paying over 200 pounds for their treatment and they are being seen by a young dentist who has just qualified, then they might be a bit concerned". (DF 3)

These concerns were expressed primarily by the dental students and foundation dentists. The foundation trainers and general dental practitioners were also aware of these apprehensions but felt that it is part of the professional cycle and confidence of a new dentist can only grow with further exposure and experience.

\section{e) Establishing Professional Relationships}

The idea of working in a new environment and adjusting with an entirely new dental team may also pose an additional challenge. This was particularly reflected by the representative of the regional deanery which regulates foundation training and foundation trainers.

"One issue which may arise is of course personality clashes which I think can be more intense in general practice. Not getting on with their nurse, maybe not getting on with their trainer or other people in the practice which can produce tensions". (Deanery Rep).

Although participants from various stakeholder groups uniformly expressed the importance of team-working and communication skills to establish professional relationships, this was stated more explicitly by the deanery representative. Perhaps 
this may be attributed to the regulatory role of the deanery as they may be required to arbitrate conflicts amongst the members of the dental team. However, it was not identified as a major issue by any of the other participants.

\section{f) Unrealistic Expectations}

Providers (dental academics and foundation trainers) also expressed their views regarding the remit of undergraduate dental education and training. They emphasized the need to recognise the limitations of undergraduate programmes both by the dental schools as well as the foundation trainers.

"Too many dental schools expect students to have covered everything and my understanding is that we need to give students the tools to be able to carry out anything new". (DA 3)

"I don't think there is anything more the dental school can do, keeping them any longer than you need to, is not helpful. You have got to let them go at some point, they toddle and fall over but they have got to the stage where they can walk and the dental school has got to let them go". (FT 2)

All foundation trainee participants in this research were satisfied with the support and feedback they received from their trainers and did not perceive their trainers to have any unrealistic expectations. However, two foundation trainees did report experiences of some of their peers whereby their trainers appeared to expect them to perform complex clinical procedures. Moreover, some trainers and a deanery representative also felt that sometimes the trainers, particularly new ones, may have very high expectations from new dental graduates. 
"I think it's to do with lowering the expectations of the trainers, especially the newer trainers ... the dilemmas occur or problems occur when trainers who have too high expectations”. (FT 1)

"Some trainers look with rose-tinted spectacles back at to how they were as graduates. Yes, I have probably done twice or three times as many of most operative procedures as a modern graduate but when I look back, I was not reasonably good at taking teeth out until I finished my senior house officer jobs". (Deanery Rep)

The perceptions of the participants about transition into foundation year are summarized in Figure 1.

\section{Strategies to improve preparedness}

The participants also made recommendations to enhance preparedness of new graduates and facilitate a smooth transition into general practice. Some of the suggestions are as follows:

a) Dental practice experience for undergraduates

Providing general dental practice experience to undergraduates was suggested as a key strategy to facilitate the transition of new graduates. This option was discussed by representatives of all stakeholder groups.

"If they are in real practice in their final year, they are probably gonna have more realistic experience, they are gonna see what surgery would be like... and would get to see how practice would run rather than being there themselves in isolation, they could see other dentists working in practice and hygienists and therapists and sort of see how the day rolls out" (DA 1) 
Although experience in general practice is recognised to be beneficial for undergraduate students, it may not be possible for students to do hands-on clinical work on patients in practice due to medico-legal issues and their visits may be limited to observation or assistance. Perhaps another alternative is to set up simulated dental practice clinics at the dental school where final year students can treat a larger number of patients during each session. Some dental schools already have such arrangements in place.

b) Pep-talks from foundation dentists

Two dental students suggested the dental schools can organise visits by foundation dentists to speak to the final year students and share their experience.

"I think something the students could do is, maybe organize for some VT to come and speak to the final year students to give them more like a ground level experience, you know you can relate better to people you know and who have just gone through the same process as you have”. (DS 2)

Although this recommendation was made by only two participants, it seems quite feasible and useful and may not have any cost implications either. Perhaps the foundation dentists owe it to their parent institution and may wish to volunteer. Moreover, social media may also be used effectively by dental students and foundation dentists to develop electronic channels of communication. 


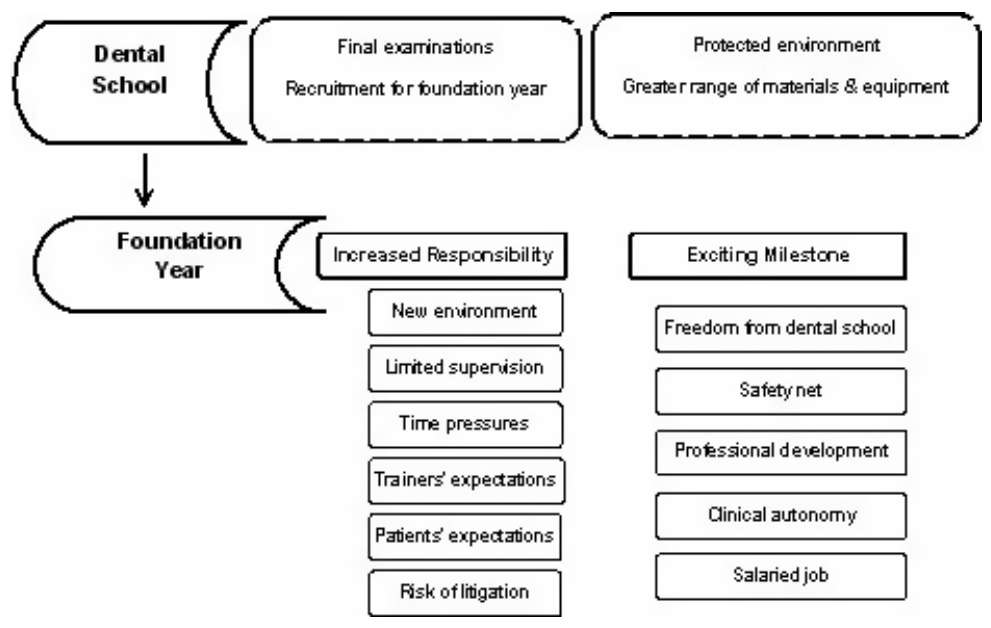

Fig. 1. Views of participants on transition from dental school to foundation training The figure illustrates the challenges of transition (left) and also identifies positive perceptions (right). 


\section{Discussion}

The findings of this study support the social context of learning in dental environments and corroborate the epistemological framework underpinning this research. Active engagement with the supervisors, integrating with the dental team, reflective practice, the ability to adapt to the general dental practice environment and interact appropriately with patients to meet their expectations are crucial to a smooth transition for new graduates. The dental students and the new graduates need to engage with their educators and the rest of the team in order to transform themselves and acquire the roles, skills, and values of the culture and community. Although dental graduates across Europe have the opportunity for internship following graduation to consolidate their skills before independent practice, most graduates spend their internship year in a dental hospital or University environment. Given that most dental graduates end up in a general dental practice environment, it may be argued that perhaps dental practices are ideal to provide a realistic experience during an internship after graduation to facilitate "situated learning".

A transition is not a moment, but rather a dynamic process in which the individual moves from one set of circumstances to another (22). A successful dental qualification is a rewarding milestone but the continuum of transition into practice often presents a steep trajectory, at least initially. Dental graduates face a common challenge to handle increased responsibilities that accompany the delivery of patient care while simultaneously learning during this process. A new graduate will take time to develop and needs several years of exposure and experience in clinical practice settings to consolidate their knowledge, skills and attitudes $(23,24)$. Competence in 
clinical practice should not be solely viewed as an achievement but rather a habit of lifelong learning (25). The data from this research also shows that transition is often perceived as a challenging and stressful experience for dental graduates and similar findings are reported in studies on medical graduates (26). Increased responsibilities and expectations for newcomers require coping strategies to ensure they can function competently in the new environment (27). There is substantial evidence in literature to show that transition may evoke stress and negative emotions (28). New graduates also recognize transition as an opening to enhance skills and experience. Given the dynamics of transition, new graduates may repetitively re-examine their role, career progression and approach and this processing may conjure positive as well as negative sentiments (22). They may adopt new behaviours or alter their context due to uncertainties and often such processing occurs at the unconscious levels (29).

Dental educators need to ensure that the dental graduates are equipped with the skills to effectively cope with the challenges of new environments so that the transition is perceived as a positive learning opportunity. Participants in this study highlighted the importance of feedback from the educators and trainers as an important factor in enhancing their skills and composure during performance. However, feedback must not be solely regarded as a responsibility of the trainer. Evidence from sociology literature shows that newcomers who proactively seek feedback from their trainers tend perform and integrate better (30). Data from this study supports these findings. Active engagement of trainees with supervisors was considered to be an important factor to facilitate their learning experiences and deal with challenging tasks. 
This study also provides further insights into the role of foundation trainers and practice environments. Transition should not be viewed solely from the trainee's perspective. The practice environment, support and feedback from trainers, nursing and administrative support, freedom in the choice of materials, equipment and clinical procedures are also likely to influence the transition during the foundation year. In this regard the personality traits of the foundation trainer may also have a significant impact on developing inter-personal relationships and how the foundation dentists seek feedback. These findings support the influence of trainer expertise highlighted in other studies (20).

High expectations of the trainers from new graduates may pose additional challenges during transition. Given limited experience of new graduates, it may be unrealistic to expect them to be competent at doing complex clinical procedures and handle challenging situations independently. It would be reasonable for the trainees to ask for help from their trainers in such situations and the trainers need to provide a positive and constructive feedback to support the learning needs of the trainees. Studies on Dental Foundation Training provide evidence of disparity in the trainer's expectations and resultant negative influences on trainees' experiences $(18,20)$.

Although the centralized recruitment for foundation training has many positives, it remains a source of stress for dental graduates and it confronts them as an additional challenge during their final year. The perceived need of participants regarding prior training for DF-1 interviews seems reasonable (31). Although provision of interview training depends on logistics and resources available at 
individual dental schools, it can provide vital support to the students in their progress towards a challenging milestone.

Participants in this study expressed the need to prioritise clinical exposure over simulated learning in order to gain a more realistic experience. Learning in simulated environments is well-established in medical and dental curricula and helps to achieve competency in a variety of skills especially before attempting irreversible operative procedures on patients. In addition to serving as a safety net, simulated learning may provide a suitable alternative to learn skills in areas where real life exposure is not possible due to lack of patient availability or limited clinical resources. Nevertheless, it seems appropriate that emphasis should be placed on providing adequate clinical exposure in undergraduate years.

A key recommendation to facilitate transition in this study was to provide a structured experience in general practice settings prior to graduation regarded as a key. There is evidence that experience in general practice in a primary care setting provides a more realistic experience of what might lie ahead and some dental schools in UK have such arrangements in place $(32,33)$. However, it remains unclear whether the students get such experience consistently across UK. In addition the participants also discussed the need for liaison between dental students and their peers in foundation training. While the strong trends in the use of social media provide an ideal platform for such interaction (34), the dental schools can play their part by organizing pep talks and provide their students with opportunities to interact with previous graduates.

Sampling for qualitative research is not random but purposive (35). For the study to be valid, a representative sample of involved individuals needs to sought. The 
"multiple realities" of any cultural context should be represented. Therefore, it is important in qualitative research to represent a variety of voices adequately, interviewing an array of subjects in an organization or profession, allowing triangulation of subjects (36). Although the participants in this study represented the key stakeholders in dental education, there was no input from the patients and this may be regarded as a limitation of this research. Perhaps it may be useful to gauge the views of patients as well in future studies. It also needs to be reiterated that although dental students and foundation dentists are at the heart of this study, they possess limited experience at this stage and it is likely their views and perceptions may change with further exposure to dental practice.

The interviews for this study were conducted by a full-time academic. Although the impact of an "insider's" influence in research remains a topic of intense debate, it is considered to be legitimate (37). It can offer several advantages to the quality of the study including familiarity with the research topic and better understanding of the participants to produce a richer data (38).

The experience of dental foundation training programme in UK over two decades may serve as a useful model to provide a structured introduction to general dental practice after graduation. The continuum of dental education does not end at the point of graduation but is a life-long process. Further research is required to explore the merits of mentoring new dental graduates in varying settings. It also needs to be mentioned that organising training of new graduates with dedicated trainers and dental practices may have significant cost implications. This may be particularly challenging due to current financial constraints in many countries. Perhaps ADEE may provide an appropriate forum to explore the internship of new dental graduates 
across Europe. This may help achieve harmonisation in training of new graduates after leaving a dental school and complement the ADEE profile of a dental graduate.

\section{Conclusions}

This study underscores the importance of a mentored year in general dental practice environment for new dental graduates and also provides insights into the challenges and benefits of transition. Given the limited clinical experience of new graduates, an additional year of supervision serves as a safety net before they become more independent. The use of general practice settings offers a realistic environment which is more closely aligned to a future career in practice. The dental foundation training programme has been in place for over two decades in UK and this study provides useful insights into the experiences and perceptions of the stakeholders. Foundation training may serve as a useful model for dental educators in Europe and beyond should they wish to revisit the transition of new dental graduates into general practice.

\section{Acknowledgements}

The authors would like to thank all the participants for their contribution to this research. We are also grateful to Professor David Moles, Director Postgraduate Dental Research, Peninsula Dental School and Dr. Alasdair Miller, Former Postgraduate Dental Dean, South West Region for their excellent support in this research project. 


\section{References}

1. ADEA Commission on Change and Innovation in Dental Education. The case for change in dental education. J Dent Educ 2006: 70: 921-924.

2. Divaris K, Barlow PJ, Chendea SA, Cheong WS, Dounis A, Dragan IF, Hamlin J, Hosseinzadeh L, Kuin D, Mitrirattanakul S, Mo'nes M, Molnar N, Perryer G, Pickup J, Raval N, Shanahan D, Songpaisan Y, Taneva E, Yaghoub-Zadeh S, West K, Vrazic D. The academic environment: the students' perspective. Eur J Dent Educ.2008; 1:120-30

3. Grant G, Elbow P, Ewens T, Gamson Z, Kohli W, Neumann W, Olesen V, Riesman D. On Competence: A Critical Analysis of Competence-Based Reforms in Higher Education (1979) Jossey-Bass, San Francisco, CA.

4. Dobbins M, Knill C. Higher education policies in Central and Eastern Europe: convergence toward a common model? Governance 22.3 (2009): 397-430.

5. Mulder M, Gulikers J, Biemans H, Wesselink R. The new competence concept in higher education: error or enrichment? Journal of European Industrial Training 33.8/9 (2009): 755-770.

6. Cowpe J, Plasschaert A, Harzer W, Vinkka-Puhakka H, Walmsley AD. Profile and competences for the graduating European dentist - update 2009. Eur $\mathrm{J}$ Dent Educ. 2010 Nov; 14(4):193-202.

7. Reynolds PA, Eaton KA, Paganelli C, Shanley D. Nine years of DentEd--a global perspective on dental education. Br Dent J. 2008 Aug 23; 205(4):199204.

8. General Dental Council. "Preparing for practice-dental team learning outcomes for registration." London: General Dental Council (2011).

9. Allen WR. Mandatory vocational training for general dental practice. Br Dent J 1993: 175: 188.

10. General Dental Council. The first five years: the undergraduate dental curriculum. 2 ${ }^{\text {nd }}$ Ed. London: General Dental Council, 2002.

11. Buck D, Malik S, Murphy N, Patel V, Singh S, Syed B, Vorah N. What makes a good dentist and do recent trainees make the grade? The views of vocational trainers. Br Dent J. 2000 Nov 25; 189(10):563-6. 
12. Bartlett DW, Coward PY, Wilson R, Goodsman D, Darby J. Experiences and perceptions of vocational training reported by the 1999 cohort of vocational dental practitioners and their trainers in England and Wales. Br Dent J. 2001 Sep 8; 191(5):265-70.

13. Patel J, Fox K, Grieveson B, Youngson CC. Undergraduate training as preparation for vocational training in England: a survey of vocational dental practitioners' and their trainers' views. Br Dent J. 2006 Sep; Suppl: 9-15.

14. Gilmour AS, Jones RJ, Cowpe JG, Bullock AD. Communication and professionalism skills of a new graduate: the expectations and experiences of dental foundation trainers. Eur J Dent Educ. 2014 Jan 28. doi: 10.1111/eje.12085.

15. Merriam SB, Caffarella RS, Baumgartner LM. Learning in Adulthood. A Comprehensive Guide, 3rd edn. San Francisco, CA: Jossey-Bass 2007; 27597.

16. Mann KV. Theoretical perspectives in medical education: past experience and future possibilities. Med Educ. 2011 Jan; 45(1):60-8.

17.Wenger E. Communities of Practice. Learning Meaning and Identity. Cambridge: Cambridge University Press. 1998; 3-15.

18. Lave J, Wenger E. (1991). Situated learning: Legitimate peripheral participation. Cambridge, UK: Cambridge University Press.

19. Ralph JP, Mercer PE, Bailey H. A comparison of the experiences of newly qualified dentists and vocational dental practitioners during their first year of general dental practice. Br Dent J. 2000 Jul 22; 189(2):101-6.

20. Cabot LB, Patel HM, Kinchin IM. Dental vocational training: identifying and developing trainer expertise. Br Dent J. 2007 Sep 22; 203(6):339-45.

21. Ali K, Tredwin C, Kay EJ, Slade A, Pooler J. Preparedness of dental graduates for foundation training: a qualitative study. Br Dent J. 2014 Aug 8; 217(3):145-9.

22. Teunissen PW, Westerman M. Opportunity or threat: the ambiguity of the consequences of transitions in medical education. Med Educ. 2011 Jan; 45(1):51-9.

23. Chambers DW. Dental curriculum and accreditation-means, ends, and the continuum. J Dent Educ 1996; 60: 816-820. 
24. Chambers DW. Problems and problem-solving strategies during the first 12 years of dental practice. J Dent Prac Admin 1989; 6: 29-34.

25. Leach DC. Competence is a habit. JAMA 2002; 287: 243-244

26. Brennan N, Corrigan O, Allard J, Archer J, Barnes R, Bleakley A, Collett T, de Bere SR. The transition from medical student to junior doctor: today's experiences of Tomorrow's Doctors. Med Educ. 2010 May; 44(5):449-58.

27. Nicholson N. A theory of work role transitions. Adm Sci Q 1984; 29:172-91.

28. Bogg J, Gibbs T, Bundred P. Training, job demands and mental health of preregistration house officers. Med Educ 2001; 35 (6):590-5.

29. Wilkie G, Raffaelli D. In at the deep end: making the transition from SpR to consultant. Adv Psychiatr Treatment 2005; 11:107-14.

30. Morrison EW. Longitudinal study of the effects of information seeking on newcomer socialisation. J Appl Psychol 1993; 78 (2):173-83.

31. Patel R, Batchelor PA. Experiences of vocational trainees on their preparation and application for vocational training. Br Dent J. 2007 Mar 24;202(6):345-9.

32. Pau AK, Croucher R. A dental practice placement scheme: benefits for practitioners and undergraduates. Eur J Dent Educ. 2001 Nov;5(4):155-61

33. Craddock HL. An evaluation of student, patient and practitioner experience of general dental practice placements. Br Dent J. 2011 Sep 23; 211(6):279-82.

34. McAndrew M, Johnston AE. The role of social media in dental education. $J$ Dent Educ. 2012 Nov; 76(11):1474-81. Review.

35. Borg WR, Gall MD. Educational research: An introduction (5th ed.) 1989. New York: Longman

36. Rubin HJ, \& Rubin IS. Qualitative interviewing: The art of hearing data (2nd ed.) 2005. Thousand Oaks, CA: Sage.

37. Corbin Dwyer, S., \& Buckle, J. The space between: On being an insideroutsider in qualitative research. International Journal of Qualitative Methods, 2009; 8(8), 54-63.

38. Tedlock, B. Ethnography and ethnographic representation. In N. K. Denzin, \& Y. S. Lincoln (Eds.). The handbook of qualitative research. London: Sage Publications. 2000 